\title{
Influence of Vernalization and Photoperiod on the Duration of Stem Elongation and Spikelet Fertility in Wheat
}

\author{
Osmar Rodrigues ${ }^{1 *}$, Mauro César Celaro Teixeira ${ }^{1}$, Edson Roberto Costenaro ${ }^{1}$, \\ Leandro Vargas ${ }^{1}$, Rafael Damo ${ }^{2}$ \\ ${ }^{1}$ Embrapa Wheat, Passo Fundo, Brazil \\ ${ }^{2}$ University of Passo Fundo, Passo Fundo, Brazil \\ Email: ${ }^{*}$ osmar.rodrigues@embrapa.br
}

Received 28 October 2014; revised 25 November 2014; accepted 4 December 2014

Copyright (C) 2014 by authors and Scientific Research Publishing Inc.

This work is licensed under the Creative Commons Attribution International License (CC BY). http://creativecommons.org/licenses/by/4.0/

\section{(c) (i) Open Access}

\section{Abstract}

A longer stem elongation phase (from the terminal spikelet-TS to the anthesis-ANT phases) increases grain production due to an increase in spikelet fertility. However, the mechanism behind the greater number of fertile flowers that occur when the duration of stem elongation is modified by photoperiod and vernalization is not fully understood. The goal of this study was to investigate the effect of combinations of photoperiod and vernalization on the duration of stem elongation and spikelet fertility in wheat. Thus, a greenhouse experiment was performed by subjecting 13 wheat genotypes to two vernalization regimes (VO-non-vernalized plants and $\mathrm{V40}-$ plants with 40 vernalization days) and to two photoperiod regimes (NP-natural and NP + 6-photoperiod extended by six hours), during the stem elongation phase. The natural photoperiod increased the spikelet fertility of eight cultivars without a corresponding increased duration of the TS-ANT phase, suggesting the existence of a direct effect of photoperiod on increased spikelet fertility. Vernalization increased the duration of the TS-ANT phase, without influencing spikelet fertility. There was genetic variability in the responses to photoperiod and vernalization.

\section{Keywords}

Double Ridge, Terminal Spikelet, Elongation

\section{Introduction}

With the evolution of wheat production of the last decades, it has been observed that not all stages of wheat de-

${ }^{*}$ Corresponding author. 
velopment are equally important for grain yield [1]. The phase between terminal spikelet initiation and anthesis (ET-ANT), characterized fast growth of the spike and stem elongation, has been suggested as having greater importance in wheat production [2]-[6]. In this phase, there is a strong relationship between spike biomass at anthesis and number of grains per area [2] [5], determining the grain yield potential. The accumulation of dry matter in the spike can be increased by extending the duration of the spike growth phase [7] [8], without expanding the total cycle of the plant until anthesis. The possibility of manipulating the duration of this phase without affecting others phases was proposed by Halloran and Pennel [9] and confirmed by Whitechurch and Slafer [10] [11]. In this sense, there is probably a genetic variability in the duration of stem elongation phase [12]-[14], which if well explored and adopted may be a strategy to increase grain yield in wheat. Thus, studies of genetic factors governing the partitioning of the developmental time have been done [15] [16] and offered as a tool for fine-tuning breeding programmers to increase the ability of wheat plants to set grains and consequently, increase crop yield. Recent studies have demonstrated that modifying the duration of this phase can change the number of grains and yield [13] [14] [17]-[23].

The length of wheat developmental phases depends on their sensitivity to photoperiod, vernalization and on their intrinsic earliness. Wheat cultivars may vary widely in their sensitivity to these conditions [1]. Thus, several studies under controlled environments and in the field have supported the use of photoperiod sensitivity to extend the duration of stem elongation and, consequently, the spike biomass at anthesis and grain production [18] [17]. The increase in spike biomass at anthesis has been positively related to the number of fertile flowers in the spike and to the number of grains [13] [18]. In spite of this relationship, Gonzallez et al. [24] observed an apparent direct effect of photoperiod (not associated with spike growth, therefore not mediated by the availability of assimilates) on the increased number of fertile flowers and grains. In that study, the authors also observed the direct effect of photoperiod on flower degeneration, and suggested that flower's death may be strongly determined by flower development rather than by the availability of photoassimilates. In another study on a wheat cultivar with a high stem elongation phase sensitivity to photoperiod and insensitivity to vernalization, Gonzallez et al. [21] detected the interaction between photoperiod and availability of photoassimilates and concluded that the main effect of photoperiod on spikelet fertility, and hence on the number of grains, was mediated by the supply of photoassimilates for spike growth. Thus, it is not completely clear if the effect of photoperiod on the increase in the number of fertile flowers and grains is mediated by the photoassimilate supply for spike growth or by the direct effect of photoperiod on spike fertility (not mediated by the supply of photoassimilates).

The effect of vernalization during stem elongation has been scarcely studied. It has been assumed that vernalization preferentially affects the duration of the vegetative phase [25] and the duration of spikelet differentiation [1]. Additionally, little is known about the interaction between vernalization and photoperiod and its influence on the duration of such phase. This issue is of great importance due to the possibility of using photoperiod sensitivity during the stem elongation phase as a strategy to increase grain numbers, and hence wheat grain yield in wheat.

This study examined the interaction between photoperiod and vernalization on the length of the stem elongation phase and number of fertile flowers in different wheat genotypes to investigated if photoperiod and vernalization may affect the number of fertile flowers and grains independently of the assimilates supply to spike growth.

\section{Material and Methods}

The experiment was conducted in the experimental area of Embrapa Trigo, Passo Fundo, in the state of Rio Grande do Sul. Plants were grown in five liters buckets [26], in a system that maintained soil moisture at field capacity, and kept in a controlled environment (greenhouse). The soil was amended with phosphorus and potassium, according to the results of the soil analysis. During the crop cycle, Hoagland's nutrient solution was applied to supply the plants with the required micronutrients, and urea was applied as topdressing during tillering (40 kg/ha). Fungicide and insecticide were applied to prevent disease and insect damage. Weeds were controlled manually.

The experiment was a split plot randomized block design, with three replications. In the main plot, two photoperiods comprised the treatments: Natural photoperiod (NP) and natural photoperiod + 6 hours (NP + 6); in the subplot, two vernalization regimes were employed: non-vernalized (V0) and vernalized for 40 days (V40), in the subplot 13 wheat genotypes were used: BRS Guamirim, BRS Louro, BRS 276, BRS Guabiju, BRS 208, BRS Umbu, BRS 277, BRS Buriti, BRS Camboatá, BRS Tarumã, BRS 296, BRS 331 and BRS 327. For verna- 
lization, seeds were imbibed in water and placed in a growth chamber at $1{ }^{\circ} \mathrm{C}$ with an 8 hour-photoperiod, for 40 days. Afterwards, seeds were sown into the pots on September $1^{\text {st }}$ (two months later than the recommended date for these cultivars) [27] to avoid natural vernalization. In each pot, 12 seeds were sown by hand, and after emergence, the five best seedlings were retained. For photoperiod supplementation we used an artificially illuminated greenhouse containing fluorescent and incandescent lamps, with automated activation was deployed.

Every two days we evaluated the following development stages: double ridge (DR), terminal spikelet (TS), anthesis (ANT) and physiological maturity (FM). For the assessment of the double ridge and terminal spikelet stages, we used a fourth replication, and the stage of apical development was determinate by dissection of the main shoot according to the scale proposed by Nerson et al. [28].

When the TS stage was reached, some buckets were taken to a second greenhouse, where they received light supplementation until anthesis. The other buckets remained in the original greenhouse (without supplementation-control). For the anthesis stage, we employed a visual assessment to determine the period when $50 \%$ of the spikes were in full bloom. At the physiological maturity stage, spikes were collected from three plants per replication, and the number of grains per spikelet was determined (each grain represented a fertile flower). Thermal time was calculated from mean air temperature using a base temperature of $0^{\circ} \mathrm{C}$.

Data were subjected to analysis of variance, means for stem elongation stage duration were compared by Tukey's test at $5 \%$ probability of error, while the flowers/spikelet fertility were compared by standard error of the mean (5\% probability of error).

\section{Results}

\subsection{Duration of Different Developmental Phases}

No significant interaction was observed between photoperiod, vernalization and cultivar on the duration of the phase between the terminal spikelet and anthesis (TS-ANT) stages. Only a simple effect of the photoperiod and vernalization on cultivars was detected. The natural photoperiod increased the duration of the TS-ANT phase only in the cultivar BRS Umbu (Table 1).

Regarding vernalization, the cultivars BRS 276, BRS Guabiju, BRS Umbu, BRS Buriti and BRS 296 had an increased TS-ANT phase duration (Table 1) when exposed to low temperatures (V40). This increase was due to the reduced period between sowing and the terminal spikelet stages (SOW-TS), once vernalization had shortened the duration of the SOW-ANT cycle (Figure 1). In the other cultivars, there was no effect of vernalization

Table 1. Duration of the period between the terminal spikelet and anthesis stages in thermal time $\left({ }^{\circ} \mathrm{Cd}\right)$ of wheat cultivars at two photoperiods (NP = natural photoperiod and NP $+6=$ natural photoperiod +6 hours extended photoperiod) and at two vernalization regimes (V40 - vernalized plants for 40 days and V0 - non-vernalized plants).

\begin{tabular}{ccccc}
\hline Cultivars & \multicolumn{3}{c}{ Photoperiod $^{*}$} & \multicolumn{2}{c}{ Vernalization $^{*}$} \\
\cline { 2 - 5 } NP & NP + 6 & V40 & $463.2 \mathrm{a}$ \\
BRS Guamirim & $443.9 \mathrm{a}$ & $434.2 \mathrm{a}$ & $415.0 \mathrm{a}$ & $503.9 \mathrm{a}$ \\
BRS Louro & $510.6 \mathrm{a}$ & $482.5 \mathrm{a}$ & $489.2 \mathrm{a}$ & $378.6 \mathrm{~b}$ \\
BRS 276 & $455.6 \mathrm{a}$ & $412.9 \mathrm{a}$ & $490.0 \mathrm{a}$ & $378.1 \mathrm{~b}$ \\
BRS Guabijú & $440.7 \mathrm{a}$ & $388.2 \mathrm{a}$ & $451.0 \mathrm{a}$ & $497.1 \mathrm{a}$ \\
BRS 208 & $502.9 \mathrm{a}$ & $512.0 \mathrm{a}$ & $517.8 \mathrm{a}$ & $430.6 \mathrm{~b}$ \\
BRS Umbu & $510.4 \mathrm{a}$ & $440.6 \mathrm{~b}$ & $520.5 \mathrm{a}$ & $448.6 \mathrm{a}$ \\
BRS 277 & $453.7 \mathrm{a}$ & $405.2 \mathrm{a}$ & $410.3 \mathrm{a}$ & $463.7 \mathrm{~b}$ \\
BRS Buriti & $509.3 \mathrm{a}$ & $481.2 \mathrm{a}$ & $526.8 \mathrm{a}$ & $481.5 \mathrm{a}$ \\
BRS Camboatá & $497.6 \mathrm{a}$ & $449.8 \mathrm{a}$ & $465.9 \mathrm{a}$ & $471.3 \mathrm{a}$ \\
BRS Tarumã & $447.5 \mathrm{a}$ & $461.1 \mathrm{a}$ & $437.3 \mathrm{a}$ & $383.1 \mathrm{~b}$ \\
BRS 296 & $443.5 \mathrm{a}$ & $436.7 \mathrm{a}$ & $497.1 \mathrm{a}$ & $442.9 \mathrm{a}$ \\
BRS 331 & $450.0 \mathrm{a}$ & $460.6 \mathrm{a}$ & $467.7 \mathrm{a}$ & $449.8 \mathrm{a}$ \\
BRS 327 & $474.2 \mathrm{a}$ & $458.0 \mathrm{a}$ & $482.3 \mathrm{a}$ & 445.6 \\
Média & 472.3 & 447.9 & 474.7 &
\end{tabular}

${ }^{*}$ Means followed by the same lower case letter, within the cultivar for photoperiod and vernalization, are not significantly different by Tukey's test at $5 \%$. 


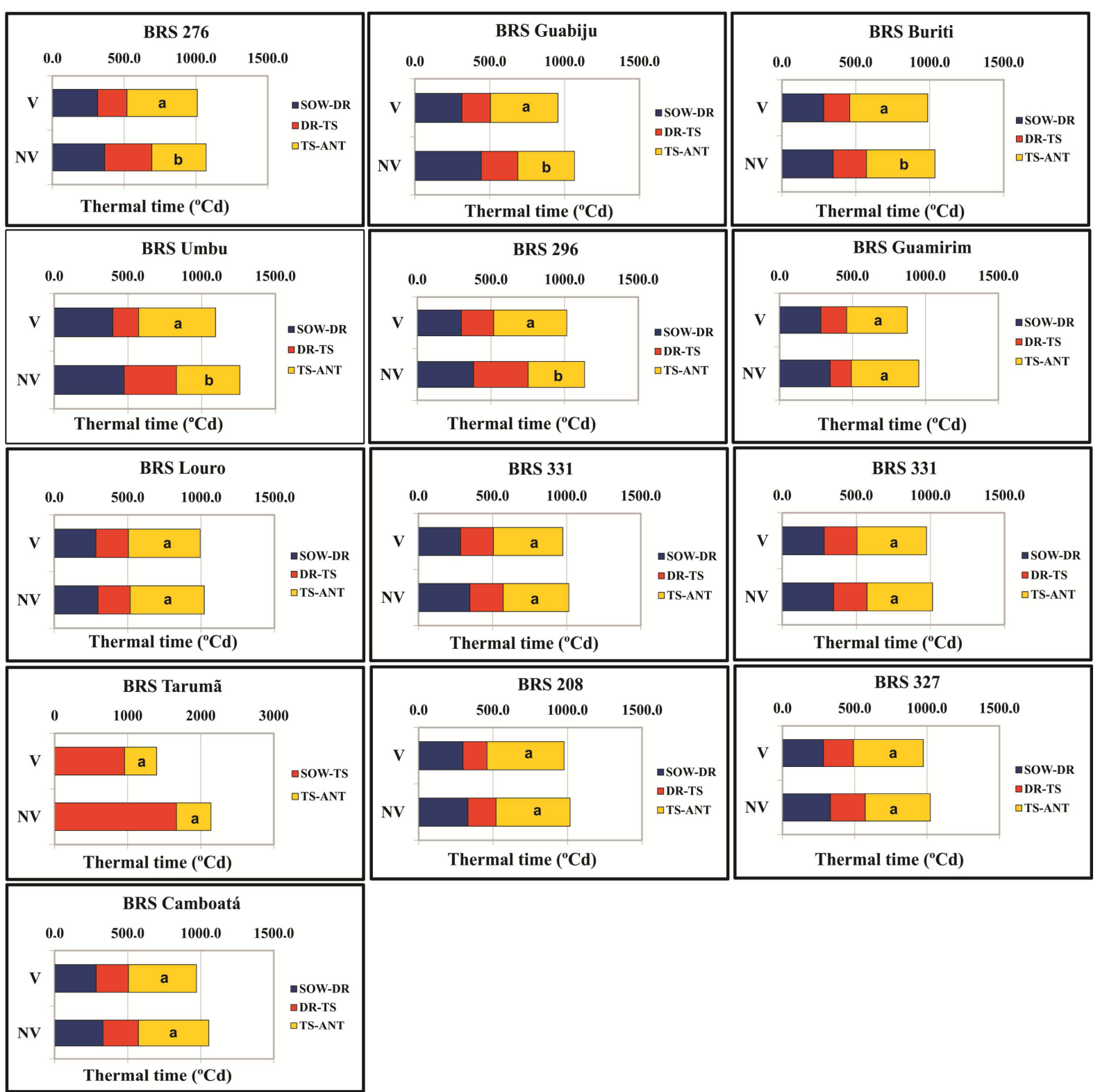

Figure 1. Duration of phenological phases in 13 wheat cultivars. Highlighted for vernalization effect on the increased length of the TS-ANT phase. Different letters in the late reproductive phase indicate a significant difference in phase duration, by Tukey's test at 5\%. V = Vernalized; NV = Non-Vernalized; SOW = Sowing; DR = Double Ridge; TS = Terminal Spikelet; and ANT = Anthesis.

on the duration of the TS-ANT phase (Figure 1). On the other hand, vernalization reduced the duration of the SOW-TS phase in the BRS Tarumã and BRS 277 cultivars, shortening the total cycle (Figure 1), although it did not change the duration of the TS-ANT phase. The other cultivars (BRS Guamirim, BRS 331, BRS Louro, Camboatá BRS, BRS 208 and BRS 327) showed no differences in the duration of SOW-TS and TS-ANT phases due to vernalization (Figure 1). The results showed that not only the duration of the vegetative phase, but also the late reproductive phase (TS-ANT) can be modified by vernalization (Figure 1).

\subsection{Flower Fertility}

The natural photoperiod (NP) increased spikelet fertility in the BRS 276, BRS Louro, BRS 208, BRS Umbu, BRS 277, BRS Buriti, BRS Camboatá and BRS 296 cultivars (Figure 2) independent of vernalization. Among 

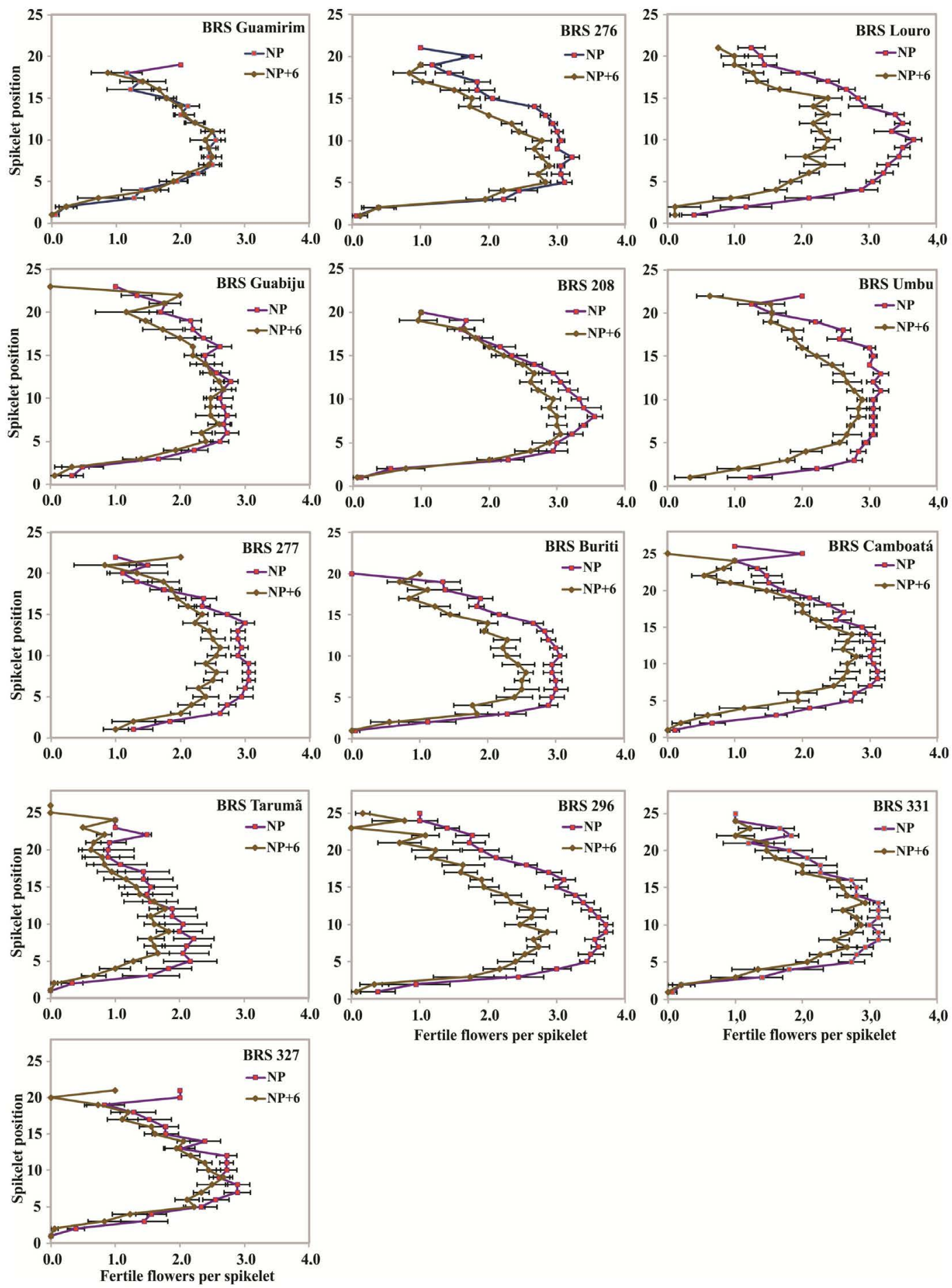

Figure 2. Number of fertile florets per spikelet position in main shoot spike at maturation under two photoperiod regimes ( $\mathrm{NP}=$ normal photoperiod and $\mathrm{NP}+6=$ normal photoperiod +6 hours) in 13 wheat cultivars, regardless of vernalization. Spikelet position on the spike follows a numerical scale, where zero (0) corresponds to the basal spikelet. Bars indicate standard error of the mean.

these cultivars, except BRS Umbu, showed no increase in TS-ANT phase duration (Table 1). All other cultivars (BRS Guamirim, BRS Guabiju, BRS 331 and BRS 327), photoperiod caused no alteration in spikelet fertility (Figure 2). 
With the exception of the BRS Tarumã, which was highly sensitive to vernalization, the spikelet fertility of the other cultivars was not affected by vernalization (Figure 3), regardless of photoperiod. Nevertheless, when the vernalization need was fulfilled, BRS Tarumã showed increased spikelet fertility due to the photoperiod effect (Figure 4). The finding that this cultivar did not increase the duration of the TS-ANT phase when exposed
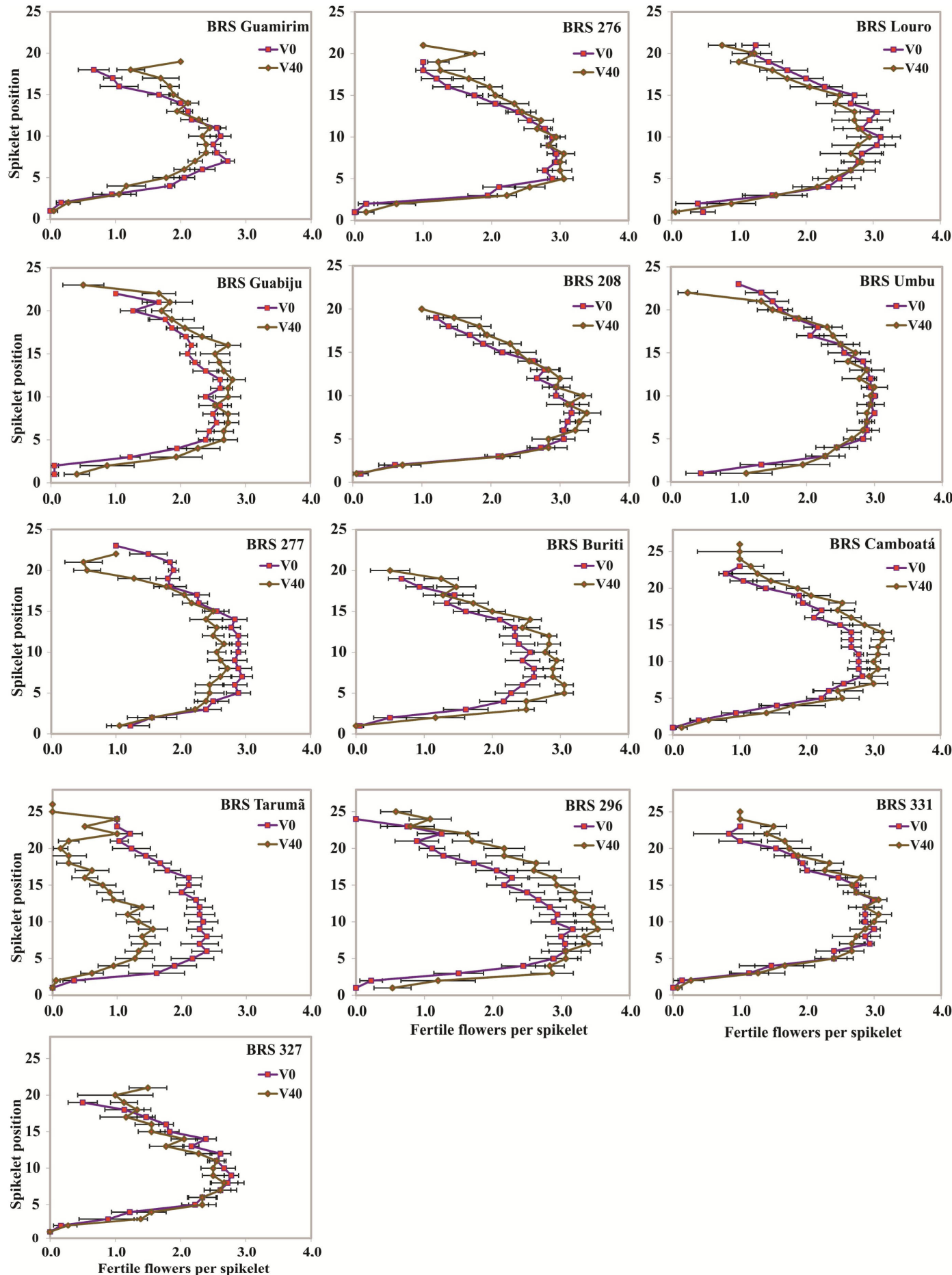

Figure 3. Number of fertile florets per spikelet position in main shoot spikes of non-vernalized (V0) and vernalized (V40) wheat, regardless of photoperiod. Spikelet position on the spike follows a numerical scale, where zero (0) corresponds to the basal spikelet. Bars indicate standard error of the mean. 

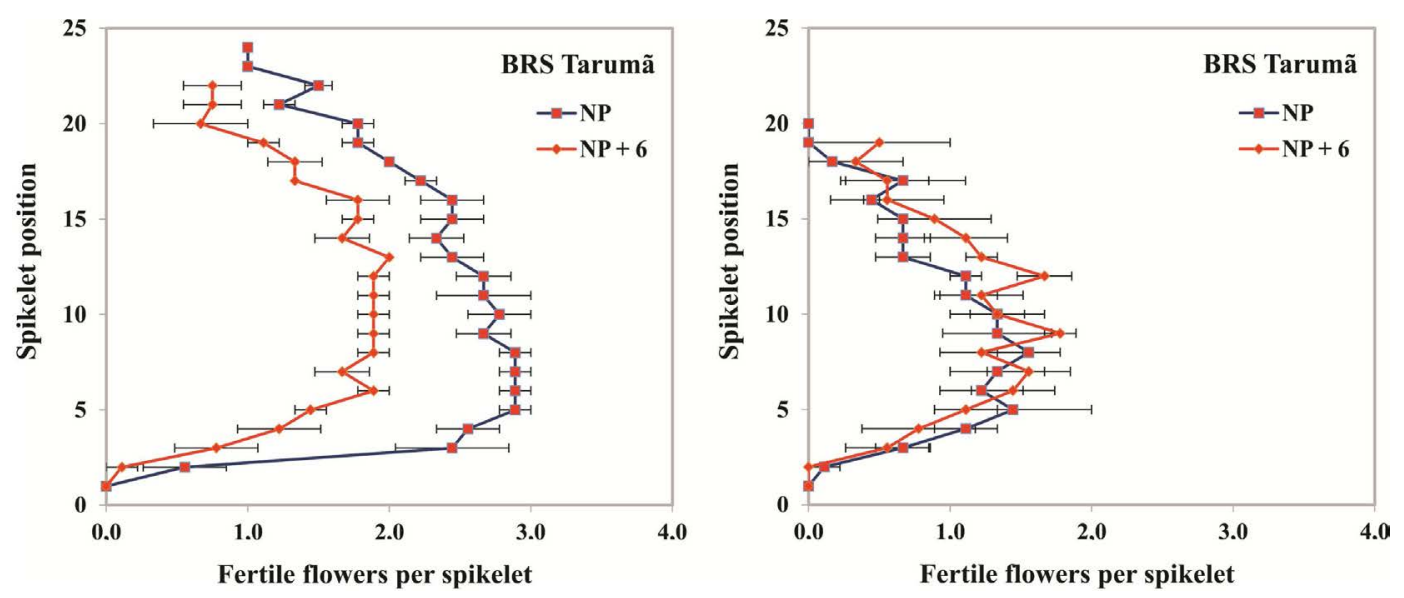

Figure 4. Fertile flowers per spikelet according to the spikelet position on the spike under two photoperiod regimes ( $\mathrm{NP}=$ natural photoperiod and $\mathrm{NP}+6=$ normal photoperiod +6 hours $)$ in the wheat genotype BRS Tarumã, vernalized (V40) and non-vernalized (V0). Spikelet position on the spike follows a numerical scale, where zero (0) corresponds to the basal spikelet. Bars indicate standard error of the mean.

to photoperiod (Table 1), but increased spikelet fertility supports the hypothesis that there is a direct effect of photoperiod on spikelet fertility.

The Cultivars BRS 276, BRS Guabijú, BRS Umbu, BRS Buriti and BRS 296 exhibited no increase in spikelet fertility due to vernalization, but rather a longer TS-ANT phase duration (Figure 1).

\section{Discussion}

The natural photoperiod increased TS-ANT phase duration only in the cultivar BRS Umbu, confirming the findings of Slafer and Rawson [1] and Miralles et al. [18], who showed that the photoperiod effect is independent for the different development phases in wheat, and highly dependent on the sensitivity of cultivars. There are cultivars with different sensitivity to photoperiod, which is due to the high genetic variability for this trait [13] [14]. The data also indicates that Embrapa's wheat breeding program of Embrapa is effective in developing and selecting wheat genotypes with a weak response to photoperiod during this phase, which allows greater amplitude of the sowing season for the same genotype as well as its indication for different regions of wheat cropping regions.

Moreover, results of the BRS Umbu cultivar emphasize the effect of photoperiod on the late reproductive phase, regardless of the response in previous phases, as proposed by Whitechurch and Slafer [11], Whitechurch et al. [14] and Gonzalles et al. [33]. These results suggest the possibility of using photoperiod sensitivity as a tool to increase ET-ANT phase duration, positively influencing grain yield. On the other hand, the results presented for this genotype contradict the hypothesis that only the vegetative and early reproductive phases are responsive to photoperiod, since the plants were subjected to a photoperiod treatment specifically during the stem elongation phase (TS-ANT). Under this condition, was removed the possibility of interference of these early phases (vegetative and early reproductive) on the stem elongation phase, as argued by Slafer and Rawson [1] and from studies by Hay [29], who used different sowing dates to expose plants to different photoperiods.

The duration of the TS-ANT phase has been considered the most important characteristic for dictating the number of grains in wheat, which is determined by spike growth during this phase [2] [30] [31]. A longer duration of this phase, provided by a short photoperiod, seems to lead to a better performance in terms of fertility in distal and less developed flowers [31], suggesting a positive correlation between the number of fertile floret per spike and length of this phase. The longer duration of this phase has also been pointed out as being responsible for the increase in spike biomass at anthesis, a result of the greater interception of radiation during this phase, and consequently increased potential grain yield [17]. Also, the increased dry weight of the spike at anthesis may be associated with the greater partitioning of biomass to the spike at anthesis, when the stem elongation phase is increased by the photoperiod due to reduced competition between the spike and stem for assimilates [13].

Gonzallez et al. [24] found that the partitioning of assimilates to the spike and the direct effect of the photo- 
period were involved in floret primordia survival, when plants were exposed to short photoperiods in the stem elongation phase. Similarly, Miralles et al. [18] and Gonzallez et al. [22] observed that the greater effect of photoperiod on the number of fertile florets and grains was due to the availability of assimilates, caused by the change in duration of the spike growth period.

The cultivars BRS 276, BRS Guabiju, BRS Umbu, BRS Buriti and BRS 296 displayed an increase in TSANT phase duration when exposed to low temperatures (V40), this increase was due to the reduced period between the sowing and terminal spikelet stages (SOW-TS), once vernalization has shortened the duration of the SOW-ANT cycle. In the other cultivars, there was no effect of vernalization on the duration of that phase. Similarly, Alberto et al. [32] investigated the BRS Louro cultivar and reported no variation in the SOW-ANT cycle duration as a function of vernalization. In our study, vernalization reduced the duration of the SOW-TS phase in the BRS Tarumã and BRS 277 cultivars, shortening the total cycle, although not changing the duration of the TS-ANT phase, as was also verified by Alberto et al. [32], who detected sensitivity of this cultivar to vernalization. These results reinforce the hypothesis of the existence of genetic variability of cultivars to vernalization. However, Gonzallez et al. [33] observed that vernalization, contrary to the findings of the present study, reduced the duration of the TS-ANT phase in the cultivars ProIINTA Puntal and ProINTA Super.

Conversely, the effect of vernalization on increasing the duration of this phase in the present study was also registered by Gonzallez et al. [13] with the cultivars Eureka Ferrocarril Sur and ProINTA Puntal subjected to a long vernalization period (V50), however these authors have found the greater response to vernalization in plants under short photoperiods. In the same way, Whitechurch et al. [14] verified an increase in the duration of that phase in plants of the cultivars Klein Estrella and ProINTA B. Alazan subjected to vernalization. This effect of vernalization on the late reproductive phase in wheat (TS-ANT) is rarely shown, as it is assumed that vernalization affects only the vegetative stages [33] and the early reproductive phase (floral initiation-TS) [1]. However, Gonzallez et al. [33] observed the influence of vernalization after the terminal spikelet stage, under noninducible conditions.

In addition, some researchers found that vernalization interacts with photoperiod during stem elongation, but the vernalization effect is smaller than that of the photoperiod [13]. In the present study, where the photoperiodic treatment was applied only during stem elongation, thus without interference of the "memory effect", interaction between these factors was not observed. On the other hand, other studies concerning the interaction of photoperiod and vernalization on wheat development use as a marker for development the duration until anthesis and relate it to the vegetative phase [1]. However, this is not completely true because the other phases, such as early reproductive (Doble Ridge-Terminal Spikelet) and late reproductive phases (TS-ANT) included in the total period (SOW-ANT), may change in opposite directions and maintain unchaged the duration of the reproductive phase. This behavior was observed in five of 13 cultivars, by examining vegetative and reproductive phases (Figure 1). In this situation, although an interaction has not been observed, the vernalization effect shortened the duration of the vegetative phase (SOW-DR) and the early reproductive phase (DR-TS), but extended the late reproductive phase (TS-ANT).

The variation on the duration between the early and late reproductive phases, keeping the total duration of the reproductive phase unchanged, may explain why some studies, which considered only the duration of the total cycle, have concluded that vernalization and photoperiod affect only the duration of the vegetative phase. We found that not only the duration of the vegetative phase, but also the late reproductive phase (TS-ANT) can be modified by vernalization. Thereby, reductions in the duration of vegetative and early reproductive phases (DR-TS) can be compensated by the extension of the late reproductive stage (TS-AN), such as in BRS Buriti. An increase in late reproductive phase duration caused by vernalization was also observed by Whitechurch et al. [14] on cultivars Klein Estrella and ProINTA B. Alazán, although the response had been lower than in the previous phase. No conclusive explanation was provided for this apparent discrepancy, even considering the distinct phenological marker (first visible node) and duration of vernalization used by the authors [14].

This study was performed with plants in a greenhouse undergoing artificial vernalization, and presented evidence that the duration of the TS-ANT phase is increased, with a reduction of the previous phases also occurring, maintaining the total duration until anthesis. On the basis of the results for BRS 276, BRS Guabijú, BRS Umbu, BRS Buriti and BRS 296, it is suggested that cultivars with a reproductive stage induced by vernalization are favored by the longer stem elongation duration and, consequently, the greater partition of biomass to the spike due to reduced competition between the spike and stem for assimilates [13], given the lack of effect on the total cycle. The results with these genotypes still support the hypothesis that phases are independent from vernaliza- 
tion and that there is a possibility of increasing wheat grain yield by using sensitivity to vernalization during this phase (TS-ANT). Thus, in Southern Brazil, with milder winters compared to USA and Europe, largest wheat producers, the sowing of cultivars more sensitive to vernalization (Mediterranean cultivars), by shortening the vegetative period, could increase the duration of the TS-ANT phase by shortening the vegetative period and consequently, grain yield. However, the abovementioned evidence does not apply to BRS Tarumã and BRS 277, which are sensitive to vernalization, and also to other vernalization insensitive cultivars.

The natural photoperiod increased the spikelet fertility in BRS 276, BRS Louro, BRS 208, BRS Umbu, BRS 277, BRS Buriti, BRS Camboatá and BRS 296 independent of vernalization. Amongst the cultivars with spikelet fertility altered by photoperiod, only BRS Umbu showed an increased duration of the TS-ANT phase. This effect of photoperiod has been related to an increase in spikelet fertility [13] [18] due to the greater availability of assimilates to the spikelets. Here, all these cultivars, except for BRS Umbu, showed no increase in the duration of the TS-ANT phase. This suggests that fertility was not controlled by the availability of assimilates from the increase in duration of the phase, reinforcing the direct effect of photoperiod on increased spikelet fertility. In this context, Gonzallez et al. [24] indicated that the partition of assimilates to spike and the direct effect of photoperiod are involved in the survival of floret primordia when the stem elongation phase is exposed to a short photoperiod.

Cultivars BRS 276, BRS Guabijú, BRS Umbu, BRS Buriti and BRS 296 exhibited no increase in spikelet fertility due to vernalization, but rather a longer TS-ANT phase duration. Therefore, the increased duration of the TS-ANT phase was not reflected in the availability of assimilates. In this way, a greater availability of assimilates due to a greater duration of TS_ANT phase, which is usually related to better spikelet fertility [13] [18] may not be directly associated.

\section{Conclusions}

In eight out of the thirteen genotypes (BRS 276, BRS Louro, BRS 208, BRS 277, BRS Buriti, BRS Camboatá, BRS Tarumã and BRS 296) exposed to natural photoperiod (NP) during stem elongation phase, an increased spikelet fertility was observed. This increase, except for the BRS Umbu, occurred without a corresponding increase in the duration of the TS-ANT phase. Thus, spikelet fertility seems not to be associated with the availability of assimilates from increased duration of the phase, indicating that there is a direct effect of photoperiod on spikelet fertility.

Vernalization increased the duration of the TS-ANT phase in the genotypes BRS 276, BRS Guabiju, BRS Umbu, BRS Buriti and BRS 296 without a corresponding increase in spikelet fertility, supporting the idea that spikelet fertility seems not to be associated with the availability of assimilates stemming from the increased duration of the phase.

\section{Acknowledgements}

We thank J. A. Marchese and T. Finatto for their technical assistance and for their critical reading and suggestions made on an early version of manuscript.

\section{References}

[1] Slafer, G.A. and Rawson, H.M. (1994) Sensitivity of Wheat Phasic Development to Major Environmental Factors: A Re-Examination of Some Assumptions Made by Physiologist and Modelers. Australian Journal of Plant Physiology, 21, 393-426. http://dx.doi.org/10.1071/PP9940393

[2] Fischer, R.A. (1985) Number of Kernels in Wheat Crops and Influence of Solar Radiation and Temperature. Journal Agricultural Science, 105, 447-461. http://dx.doi.org/10.1017/S0021859600056495

[3] Kirby, E.J.M. (1988) Analysis of Leaf, Stem and Ear Growth in Wheat from Terminal Spikelet Stage to Anthesis. Field Crops Research, 18, 127-140. http://dx.doi.org/10.1016/0378-4290(88)90004-4

[4] Siddique, K.H.M., Kirby, E.I.M. and Perry, M.W. (1989b) Ear: Stem Ratio in Old and Modern Wheat Varieties; Relationship with Improvement in Number of Grain per Ear and Yield. Field Crops Research, 26, 59-78. http://dx.doi.org/10.1016/0378-4290(89)90041-5

[5] Savin, R. and Slafer, G.A. (1991) Shading Effect on the Yield of an Argentina Wheat Cultivar. Journal of Agricultural Science, 116, 1-7. http://dx.doi.org/10.1017/S0021859600076085

[6] Slafer, G.A., Satorre, E.H. and Andrade, F.H. (1994) Increases in Grain Yield in Bread Wheat from Breeding and As- 
sociated Physiological Changes. In: Slafer, G.A., Ed., Genetic Improvement of Field Crops: Current Status and Development, Marcel Dekker, Inc., New York, 1-68.

[7] Slafer, G.A., Calderini, D.F. and Miralles, D.J. (1996) Yield Components and Compensation in Wheat: Opportunities for Further Increasing Yield Potential. In: Reynolds, M.P., Rajaram, S., Mcnab, A., Eds., Increasing Yields Potential in Wheat: Breaking the Barries, Mexico D.F., 101-133.

[8] Araus, J.L., Slafer, G.A., Reinolds, M.P. and Royo, C. (2002) Plant Breeding and Drought in C3 Cereal: What Should We Breed for? Annals of Botany, 89, 925-940. http://dx.doi.org/10.1093/aob/mcf049

[9] Halloran, G.M. and Pennel, A.L. (1982) Duration and Rate of Development Phases in Wheat in Two Environments. Annals of Botany (London), 49, 115-121.

[10] Whitechurch, E.M. and Slafer, G.A. (2001) Responses to Photoperiod before and after Jointing in Wheat Substitution Lines. Euphytica, 118, 47-51. http://dx.doi.org/10.1016/S0378-4290(01)00188-5

[11] Whitechurch, E.M. and Slafer, G.A. (2002) Contrasting Ppd Alleles in Wheat: Effects on Sensitivity to Photoperiod in Different Phases. Field Crops Research, 73, 95-105. http://dx.doi.org/10.1016/S0378-4290(01)00188-5

[12] Kirby, E.J.M., Spink, J.H., Frost, D.L., Sylvester-Bradley, R., Scott, R.K., Foulkes, M.J., Clare, R.W. and Evans, E.J.A. (1999) Study of Wheat Development in the Field: Analysis by Phases. European Journal of Agronomy, 11, 63-82. http://dx.doi.org/10.1016/S1161-0301(99)00022-2

[13] Gonzalez, F.G., Slafer, G.A. and Miralles, D.J. (2003) Grain and Floret Number in Response to Photoperiod during Stem Elongation in Fully and Slightly Vernalized Wheat. Field Crops Research, 81, 17-27. http://dx.doi.org/10.1016/S0378-4290(02)00195-8

[14] Whitechurch, E.M., Slafer, G.A. and Miralles, D.J. (2007) Variability in the Duration of Stem Elongation in Wheat Genotype and Sensitivity to Photoperiod and Vernalization. Journal of Agronomy Crop Science, 193, 131-137. http://dx.doi.org/10.1111/j.1439-037X.2007.00259.x

[15] Borras-Gelonch, G., Rebetzke, G.J., Richards, R.A. and Romagosa, I. (2012) Genetic Control of Duration of Pre-Anthesis Phases in Wheat (Triticum aestivum L.) and Relationships to Leaf Appearance, Tillering, and Dry Matter Accumulation. Journal Experimental Botany, 63, 69-89. http://dx.doi.org/10.1093/jxb/err230

[16] Sanna, G., Giunta, F., Motzo, R., Mastrangelo, A.M. and De Vita, P. (2014) Genetic Variation for the Duration of PreAnthesis Development in Durum Wheat and Its Interaction with Vernalization Treatment and Photoperiod. Journal of Experimental Botany, 65, 3177-3188. http://dx.doi.org/10.1093/jxb/eru170

[17] Slafer, G.A., Abeledo, L.G., Miralles, D.J., Gonzalez, F.G. and Whitechurch, E.M. (2001) Photoperiod Sensitivity during Stem Elongation as an Avenue to Raise Potential Yield in Wheat. Euphytica, 119, 191-197. http://dx.doi.org/10.1023/A:1017535632171

[18] Miralles, J.D., Richards, R.A. and Slafer, G.A. (2000) Duration of the Stem Elongation Period Influences the Number of Fertile Florets in Wheat and Barley. Australian Journal of Plant Physiology, 27, 931-940.

[19] Slafer, G.A. and Whitechurch, E.M. (2001) Manipulating Wheat Development to Improve Adaptation. In: Reynolds, M.P., Ortiz-Monasterio, J.I. and Mcnab, A., Eds., Application of Physiology in Wheat Breeding, CIMMYT, Mexico D.F., $160-170$.

[20] Slafer, G.A. (2003) Genetic Basis of Yield as Viewed from a Crop Physiologist's Perspective. Annals of Applied Biology, 142, 117-128. http://dx.doi.org/10.1111/j.1744-7348.2003.tb00237.x

[21] Gonzalez, F.G., Slafer, G.A. and Miralles, D.J. (2005) Photoperiod during Stem Elongation in Wheat: Is Its Impact on Fertile Floret and Grain Number Determination Similar to That of Radiation? Functional Plant Biology, 32, 181-188. http://dx.doi.org/10.1071/FP04103

[22] Gonzalez, F.G., Slafer, G.A. and Miralles, D.J. (2005) Pre-Anthesis Development and Number of Fertile Florets in Wheat as Affected by Photoperiod Sensitivity Genes $P p d-D_{1}$ and $P p d-B_{1}$. Euphytica, 146, 253-269. http://dx.doi.org/10.1007/s10681-005-9021-3

[23] Fischer, R.A. (2008) The Importance of Grain or Kernel Number in Wheat: A Reply to Sinclair and Jamieson. Field Crop Research, 105, 15-21. http://dx.doi.org/10.1016/j.fcr.2007.04.002

[24] Gonzalez, F.G., Slafer, G.A. and Miralles, D.J. (2003) Floret Development and Spike Growth as Affected by Photoperiod during Stem Elongation in Wheat. Field Crop Research, 81, 29-38. http://dx.doi.org/10.1016/S0378-4290(02)00196-X

[25] Robertson, M.J., Brocking, I.R. and Ritchie, T.J. (1996) Temperature Response of Vernalization in Wheat: Modeling the Effect on the Final Number of Main Stem Leaves. Annals of Botany, 78, 371-381. http://dx.doi.org/10.1006/anbo.1996.0132

[26] Rodrigues, O., Lhamby, J.C.B., Didonet, A.D., Marchese, J.A. and Scipioni, C. (1998) Efeito da deficiência hídrica na produção de trigo. Pesquisa Agropecuária Brasileira, 33, 839-846. 
[27] RCBPTT (2008) Reunião da Comissão Brasileira de Pesquisa de Trigo e Triticale. In: Informações técnicas para a safra 2008: Trigo e triticale, Embrapa Soja, Londrina, 147 p.

[28] Nerson, H., Sibony, M. and Pinthus, J.M. (1980) A Scale for the Assessment of the Developmental Stage of the Wheat (Triticum aestivum L.) Spike. Annals of Botany, 45, 203-204.

[29] Hay, R.K.M. (1986) Sowing Date and the Relationships between Plant and Apex Development in Winter Cereals. Field Crops Research, 14, 321-337. http://dx.doi.org/10.1016/0378-4290(86)90067-5

[30] Slafer, G.A. and Andrade, F.H. (1993) Physiological Attributes Related to the Generation of Grain Yield in Bread Wheat Cultivars Released at Different Eras. Field Crops Research, 31, 351-367. http://dx.doi.org/10.1016/0378-4290(93)90073-V

[31] Miralles, D.J., Katz, S.D., Colloca, A. and Slafer, G.A. (1998) Floret Development in Near Isogenic Wheat Lines in Differring in Plant Height. Field Crops Research, 59, 21-30. http://dx.doi.org/10.1016/S0378-4290(98)00103-8

[32] Alberto, C.M., Streck, N.A., Walter, L.C., Rosa, H.T., Brackmann, A., Oliveira, F.B., Zanon, A.J. and Fagundes, L.K. (2009) Resposta à vernalização de cultivares brasileiras de trigo. Bragantia, 68, 535-543. http://dx.doi.org/10.1590/S0006-87052009000200029

[33] Gonzalez, F.G., Slafer, G.A. and Miralles, D.J. (2002) Vernalization and Photoperiod Responses in Wheat Pre-Flowering Reproductive Phases. Field Crops Research, 74, 183-195. http://dx.doi.org/10.1016/S0378-4290(01)00210-6 
Scientific Research Publishing (SCIRP) is one of the largest Open Access journal publishers. It is currently publishing more than 200 open access, online, peer-reviewed journals covering a wide range of academic disciplines. SCIRP serves the worldwide academic communities and contributes to the progress and application of science with its publication.

Other selected journals from SCIRP are listed as below. Submit your manuscript to us via either submit@scirp.org or Online Submission Portal.
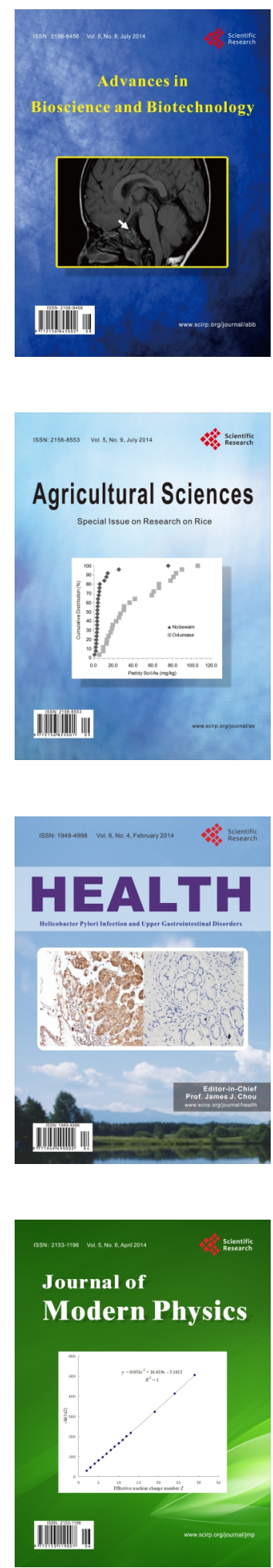
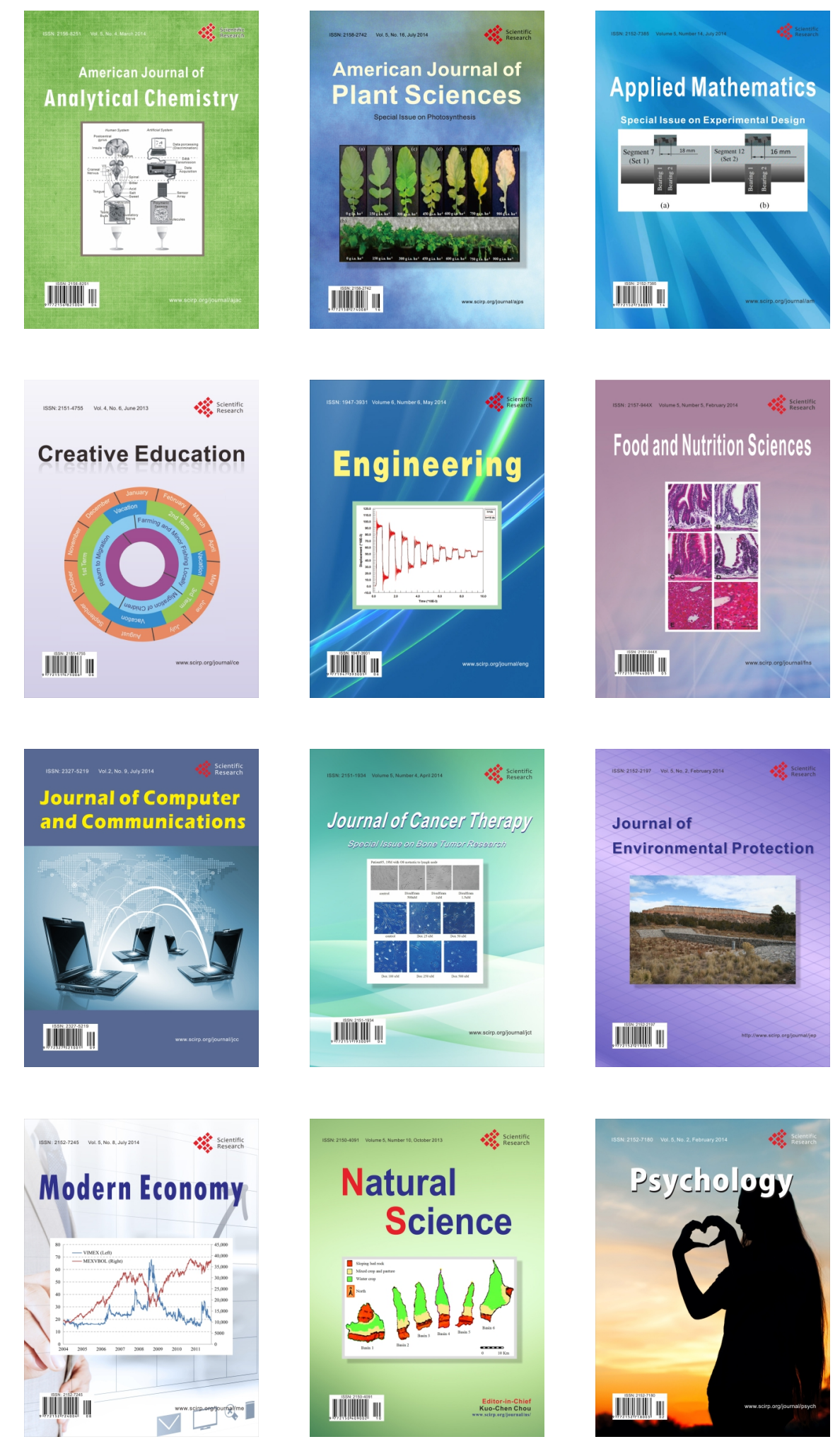